\title{
A New Approach based on a Multi-ontologies and Multi- agents System to Generate Customized Learning Paths in an E-Learning Platform
}

\author{
Jaber El Bouhdidi \\ Laboratory LIST \\ FST-Tangier \\ Tangier-Morocco
}

\author{
Mohamed Ghailani \\ Laboratory LIST \\ FST-Tangier \\ Tangier-Morocco
}

\author{
Otman Abdoun \\ Laboratory LIST \\ FST-Tangier \\ Tangier-Morocco
}

\author{
Abdelhadi Fennan \\ Laboratory LIST \\ FST-Tangier \\ Tangier-Morocco
}

\begin{abstract}
Currently the Multi-Agents System (MAS) have discussed several areas such as in the field of education. The MAS is one of the most promising technological paradigms in the development of distance learning platforms. They can contribute greatly to improve the teaching/learning process.

In this paper we propose a model of E-Learning based on a process of coupling of ontologies and multi-agent systems for a synergy of their strengths. Indeed, this model allows human agents (students, teachers and instructional designers) to cooperate with software agents to automatically build courses guided by relevant learning objectives. In addition, it allows the learner to follow his training at their own pace and according to their preferences, either individually or jointly with others (students or tutors).
\end{abstract}

Therefore, the proposed model provides learners with a training respecting their preferences and meets their expectations. And this is by creating of customized resources for a quality relevant educational use.

\section{General Terms}

E-Learning, Web semantic, Multi-Agents System, Pedagogical Objective.

\section{Keywords}

Multi-ontologies, MAS, Pedagogical Objective, Educational Service.

\section{INTRODUCTION}

Initially, artificial intelligence (AI) is an area that has been exhausted by specialists for several years. Its integration into the environments of distance learning has become unavoidable to the extent that its techniques help make these environments more dynamic and adaptive.

The multi-agent systems (MAS) are part of artificial intelligence. They have emerged today in the development of major applications; namely the platforms of distance education. Indeed, the agent technology begins to be used to design stable and flexible solutions based on a set of agents which are in constant communication to accomplish the tasks entrusted to them. Whereas, inter-agent communication must be based on messages understandable by the different entities. Therefore, we will think of a way (solution) to ensure this common understanding of the content of messages exchanged. The ontology is a framework for response to this challenge $[1,2]$. It has a vital role in sharing and in representing in formal way knowledge in a form usable by computer agents.

In this paper, we propose a model on E-Learning based on a coupling of ontologies and multi-agent systems to automate the creation of objectives-oriented courses defined by the instructional designer. Pre-tests and post-tests are proposed by the model for the success of the goal. These terms of input/output are determined by the creator of educational service, before its publication in order to respond effectively to the needs of a group of learners consumers, while engaging in the service profile to be published.

The categorization of learners is done through the system based on their profiles (preferences, learning style, knowledge and skills, etc.). It retrieves the profile of the learner in his first connection to be assigned to a class of learners existing or newly created to another if it belongs to none. For students already enrolled on, the system requires change in their membership class if their performance is modest.

In short, the proposed system will enable human agents (students, teachers and instructional designers) on one hand, to cooperate with software agents in order to build a training relevant, and on the other hand, to allow the student to take support training at its option, either individually or jointly with others (students or tutors) while relying on the classes of existing or newly created profiles.

The rest of this article is structured as follows: Section 2 discusses the pedagogical approach and the structuring of modules to teach. Section 3 presents the main features of the system: the representation of roles of all agents and their interactions. Section 4 presents a scenario of the dynamic construction of customized learning paths. Then, we end up with a conclusion.

\section{PEDAGOGICAL APPROACH}

To design learning paths which are tailored to the profiles of trainers, we decided to adopt the Pedagogy By Goals [3]. Students must submit their needs in the form of educational objectives which are the results they want to achieve at the end of their training. This requires fine structure concepts for optimal use. 
That is why we adopted the Pedagogy By Goals (PBG). PBG is a methodology that breaks up a teaching module in its complex and simple elements essential to facilitate the teaching / learning process and assessment. The decomposition is performed on the basis of educational objectives.

\subsection{Structure of the Training Modules}

Our architecture is based on the pedagogy by goals to structure the material to teach (i.e. the learning module), we use a threelevel hierarchy of educational objectives as defined in [4]:

1. The General Objectives or abstract (GO);

2. The Specific Objectives or composite (SO);

3. The Operational Objectives or atomic $(\mathbf{O O})$;

To classify these objectives, we opted for the taxonomy of cognitive domain by Benjamin BLOOM, who is the father of the first hierarchical classification of educational objectives. The taxonomy of educational objectives BLOOM [5,6], is composed of six levels, including: knowledge, comprehension, application, analysis, synthesis and evaluation. For each class, there is a set of verbs that can be used to express the objectives of educational services.

This hierarchy has allowed us to consider three levels of abstraction module of instruction:

1. Parts (meeting the General Objectives);

2. Chapters (that meets the Specific Objectives);

3. Hypermedia Learning Units (HLUs) (meeting the operational objectives).

These are transfer credits evaluated. The system, then, organizes the process of education around these components hypermedia (the HLUs). The HLUs are supposed to receive, by instantiation, all kinds of domain knowledge in all forms of media permitted by HTML (text, image, sound, video, script, applet), Figure 1 shows the structure of a module into simple elements.

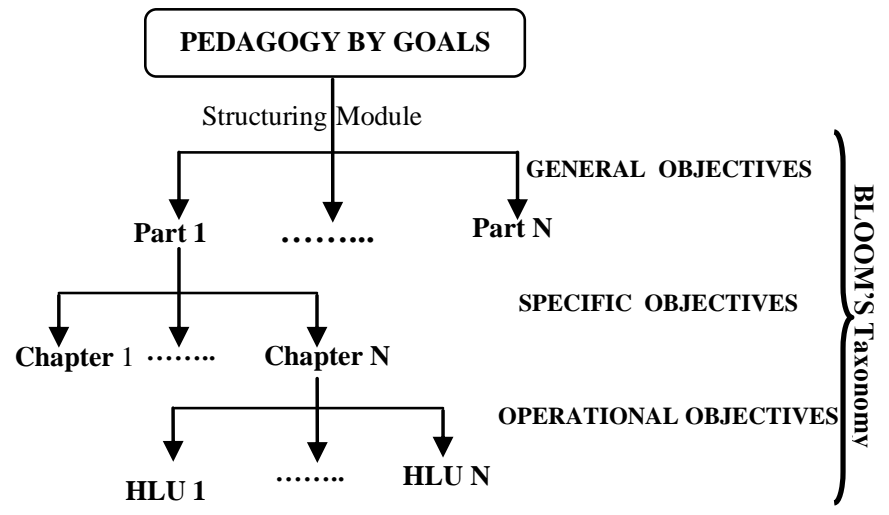

Figure 1: Hierarchical representation of a module

Based on the tactics (say, show, do), the HLUs courses present the theory on the subject to teach (say) and examples can show (show) the student how to apply theory to practical examples. The evaluation HLUs buttons serve to measure the achievement of operational objectives for the learner, and this, by pushing to do (do) by himself the application of management theory study. Managements of HLUs in the canvas of tutor, is ensured by a system based on a multi-agent system and multi-ontologies, and based on five packets of rules:

1. Negotiation of learning objectives;

2. Estimated acquired after trading;
3. Planning sequences of HLUs;

4. Search, filtering and display of the learning paths;

5. Evaluation of the learner.

The sequence of learning objectives (LOs) by the system is made on the basis of a "network of pre-requisites" proposed by the author of the teaching module. A prerequisite link between two objectives LO1 and LO2 (from LO1 to LO2) defines on the one hand a precedence desired by the author between the two objectives, proposing that learning the second objective cannot be completed until LO2 achievement (or success) of the first goal LO1, on the other hand, a link indicative of progression or a remediation of a potential link. This latter feature means that the system can choose a $\mathrm{LO}$ that is a pre-requisite to a $\mathrm{LO}$ on which the learner has failed in order to offer him a contribution of knowledge that relates to the LO prerequisites.

\subsection{Educational Service}

In this approach, we consider that a service is a type of component with the properties of autonomy, reuse and sharing. A service description has a semantics that allows to specify the context in which we can reuse and the use that we can do. A service learning is a fragment of processes to achieve an educational objective. The notion of teaching objective is to define appropriate use of a service (its purpose) but also to express variability. Indeed, the same objective can be achieved in different ways, depending on the learner profile, preferences ...etc. The process dimension is another important aspect of services. It can take into account the different teaching methods and strategies in defining learning paths.

Each educational service is characterized by a "profile" that describes the general appearance of educational service (service interface). It has an objective, background and way. It will be used when looking for a match between available services on the one hand, and intentions of learners, on the other (Table 1).

Table1: Representation of a service

\begin{tabular}{|l|l|l|}
\hline \multicolumn{2}{|c|}{ Educational Service } \\
\hline \multirow{4}{*}{0} & \multirow{3}{*}{ Objective } & Type \\
\cline { 3 - 3 } & & Verb \\
\cline { 3 - 3 } & $\begin{array}{l}\text { Concept ( object of } \\
\text { instruction) }\end{array}$ \\
\cline { 3 - 3 } & \multirow{2}{*}{ Background } & Area taught \\
\cline { 3 - 3 } & Level \\
\cline { 3 - 3 } & Way & Strategy \\
\cline { 3 - 3 } & & Method \\
\hline
\end{tabular}

\subsection{Dynamic Composition of Services}

The process of creating the paths allows to search / select services and assembles these services to generate personalized learning paths and reusable result of demands of learners. It is during the generation of the learning paths that links between educational services are established. The principle of dynamic composition is essential to build personalized learning paths. This principle is applied by two agents (Tests builder Agent) and Contents Builder Agent) at the time of its generation to be provided to the learner. If the goal formulated by the learner is abstract (GO), the GO is sub-divided into operational objectives 
(OO) that can satisfy it (Fig.2). Then, we select, based on learner

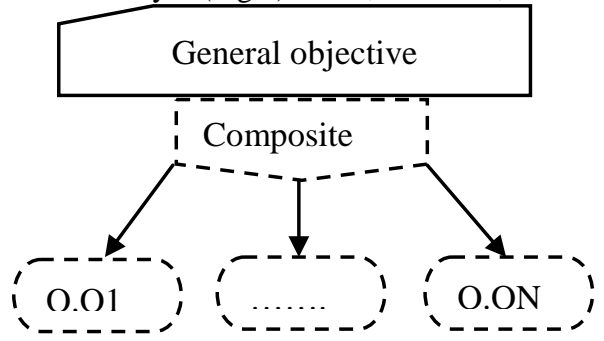

Figure 2: Decomposition of a General Objective

profile, services which meet operational goals. It is in this stage that links are established between services.

\section{DESIGNING A MULTI-AGENTS AND MULTI-ONTOLOGIES ARCHITECTURE}

Learners have a different styles, knowledge, and preferences of learning. The proposed architecture will resolve the problem of difference between learners through the creation of resources and optimal learning paths and customized to each learner. To improve the relevance of research services, we propose in this paper an approach based on using ontology to classify targets in a hierarchical goals and an ontology of educational resources for document indexing, and use of semantic links between the services of a journey, the ontology of the borrowed resources SCORM [7] which defines a tree structure representation. These ontologies are managed by a multi-agent system to generate custom learning paths. This model has the advantage of providing a mechanism of semantics between the profile of educational services and that of the learner to choose the "best" service i.e. the service most suitable both in terms of educational level and in terms of preferences (audio, video, language,...etc).

The system is designed so that each of its actors (teachers, learners and instructional designers) can accomplish their tasks: The teacher is the person responsible for the task of teaching and/or mentoring in a training process, he may also add to the pool system during all well-structured and annotated courses based on the ontology of educational resources which describes the structure of a course material.

The learner seeks to acquire knowledge and understanding of knowledge in a particular area, and this by formulating an objective (general, specific or operational). As for the instructional designer, he collaborated in planning the whole course, and writes it. He offers relevant learning activities and ensures congruence between the objectives, content and evaluation. The diagram in Figure 3 illustrates the actions of various entities of the system.

\subsection{Communication Between Agents}

The communication between agents is a primary property of Multi-Agent Systems (MAS) [8,9]. It increases the prospects of officers in their concurring in the benefits of information and know-how of other agents. The communication between agents is a fundamental means to ensure the distribution of tasks and coordination of actions between them. FIPA player in the field of SMA's main task is to develop a standard for communication between agents [10]. One of his achievements is the standard FIPA-ACL, there is another one which is KQML [11].

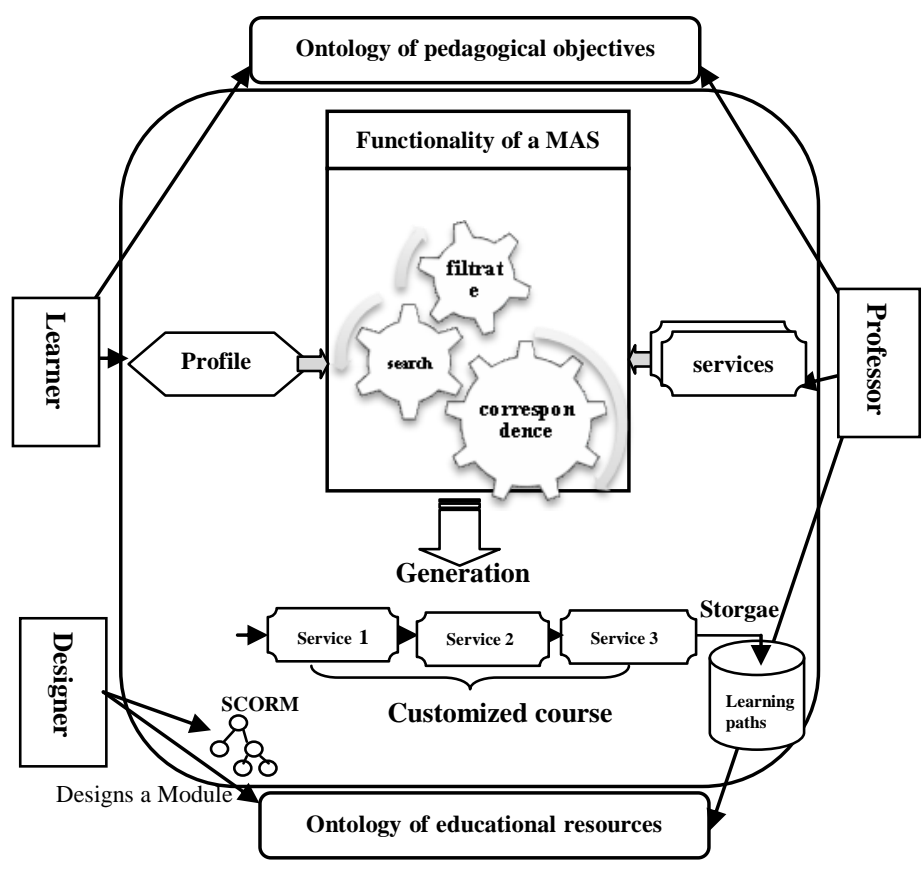

Figure 3: General diagram of system

An Agent Communication Language (ACL) must be designed to exchange information between agents, knowledge or services. The ontology will provide specific vocabularies depending on scope for communication between agents and define the concepts and relationships that exist between the words of a formal vocabulary for the agents to use. Subsequently, the agents of a MAS share a common ontology (common vocabulary).

\subsection{The Proposed Architecture}

The architecture we propose is based on flexible modules (agents) that allow interaction with the learner to offer training at its option. These agents are in permanent communication; it is managed by a manager agent. These agents can manage all parts of the architecture, coordinate the process, build personalized learning paths and perform testing of pre-conditions and postconditions for each course. The proposed architecture is based on six agents (Fig. 4):

- Interface Agent (IA);

- Manager Agent (MA);

- Contents Builder Agent (CBA);

- Tests Builder Agent (TBA);

- $\quad$ Profile Manager Agent (PMA);

- Filter Agent (FA);

\subsubsection{Interface Agent (IA)}

It is an agent who acts as the interface between the learner and other agents through Manager Agent. The interface agent uses two means of communication the HTTP protocol for communication with the learner (the browser) and the language KQML for communication with other agents. It receives the request of the learner as an HTTP request, it formulates a query and sends KQML to the Manager Agent. It dissects the query to retrieve the identifier of the learning and demand from Profile Manager Agent (PMA) level, of concept(s) requested to the 
learner in question. IA can also receive the request for registration of a new learner or the connection request from a learner already registered (HTTP) and sends it to the PMA through the MA. It also sends the results of all assessments (Quizzes, test, and exercise) to change the profile of the learner.

\subsubsection{Manager Agent (MA)}

This agent controls all the operations performed by the system and assigns tasks to agents according to their roles they were assigned to. The agent manager once receives a request from the Interface Agent, it determines its nature in order to select agents that can contribute to fulfill this request. The requests exchanged between the IA and MA are listed and are easily identified by an id number. MA acts according to the type of complaint: course request, evaluation request, login, registration, profile editing ... etc.

\subsubsection{Contents Builder Agent (CBA)}

It receives from MA a request formulated by the learner and the level(s) concept(s) request(s). It queries the ontology of the objectives to determine the type of goal made (General objective, specific or operational) and reformulates the query so that it includes, in addition to the concepts, the learner profile and type of its goal, and sends it to the filter agent. The latter, searches and selects services (one or more HLUs) that match the query (target and learner profile) after the filtering agent's response, it applies the principle of dynamic composition of services to organize and produce a learning path executed by the learner, and then it sends it to the Manager Agent.

\subsubsection{Tests Builder Agent (TBA)}

It receives from MA a request containing the concept (s) to evaluate and the goal. The TBA demands from the FA to search and select services (assessments) that match the specified criteria. After the response of the FA, TBA applies the principle of dynamic composition of services to have a proper evaluation.

\subsubsection{Filter Agent (FA)}

The role of the Filter Agent is a search service based on criteria specified by the CBA or TBA, and then he responds by sending the addresses of services received. when the FA receives the search request containing the service (s) concept (s) it seeks the services container (s) concept (s) and then filters among all these services which meet those levels cognitive learner, while resting the learner profile. Another filter is applied to the content services, to filter service(s) adequate(s) in physical type of media preferred by the learner.

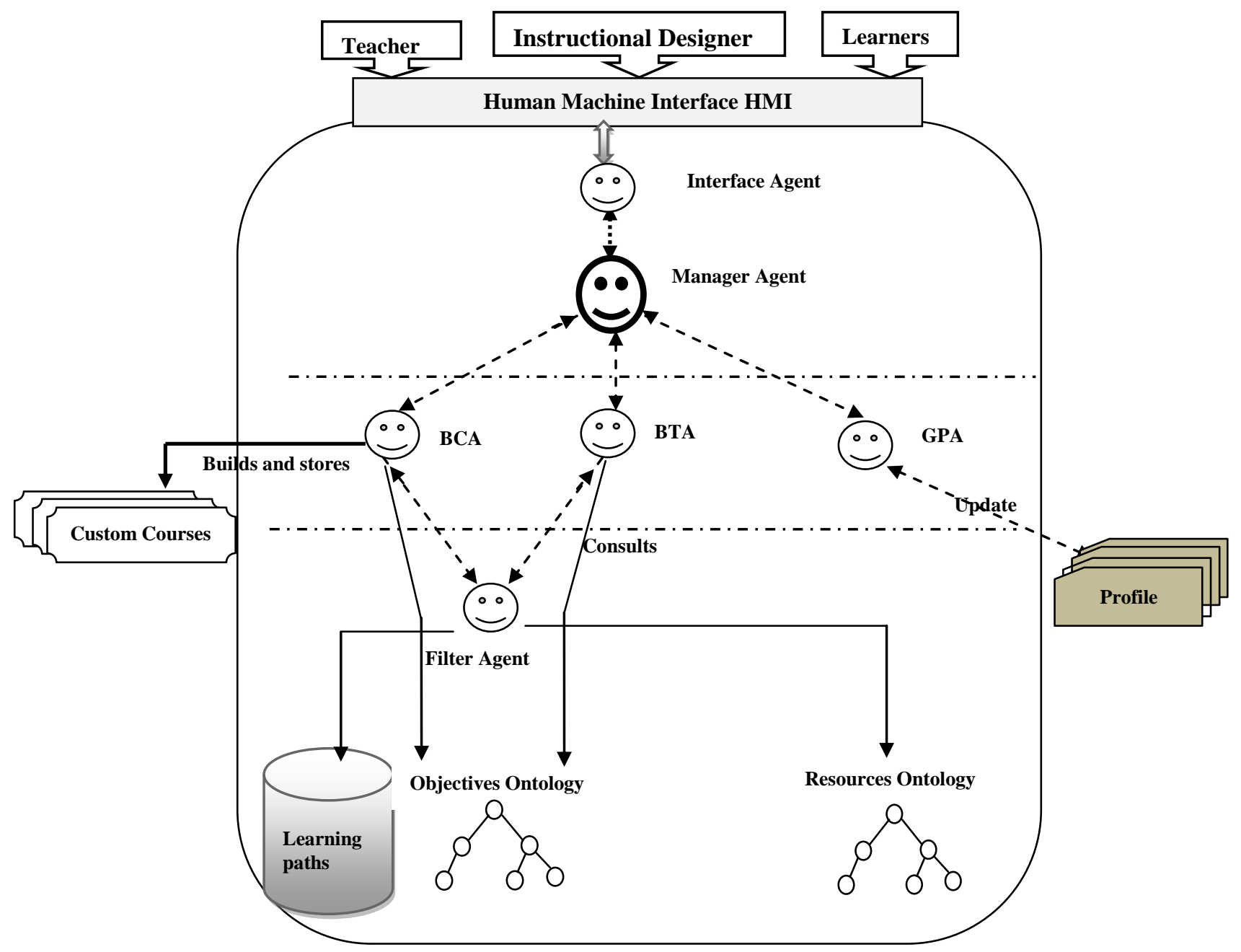

Figure 4: Modeling architecture based on a MAS 


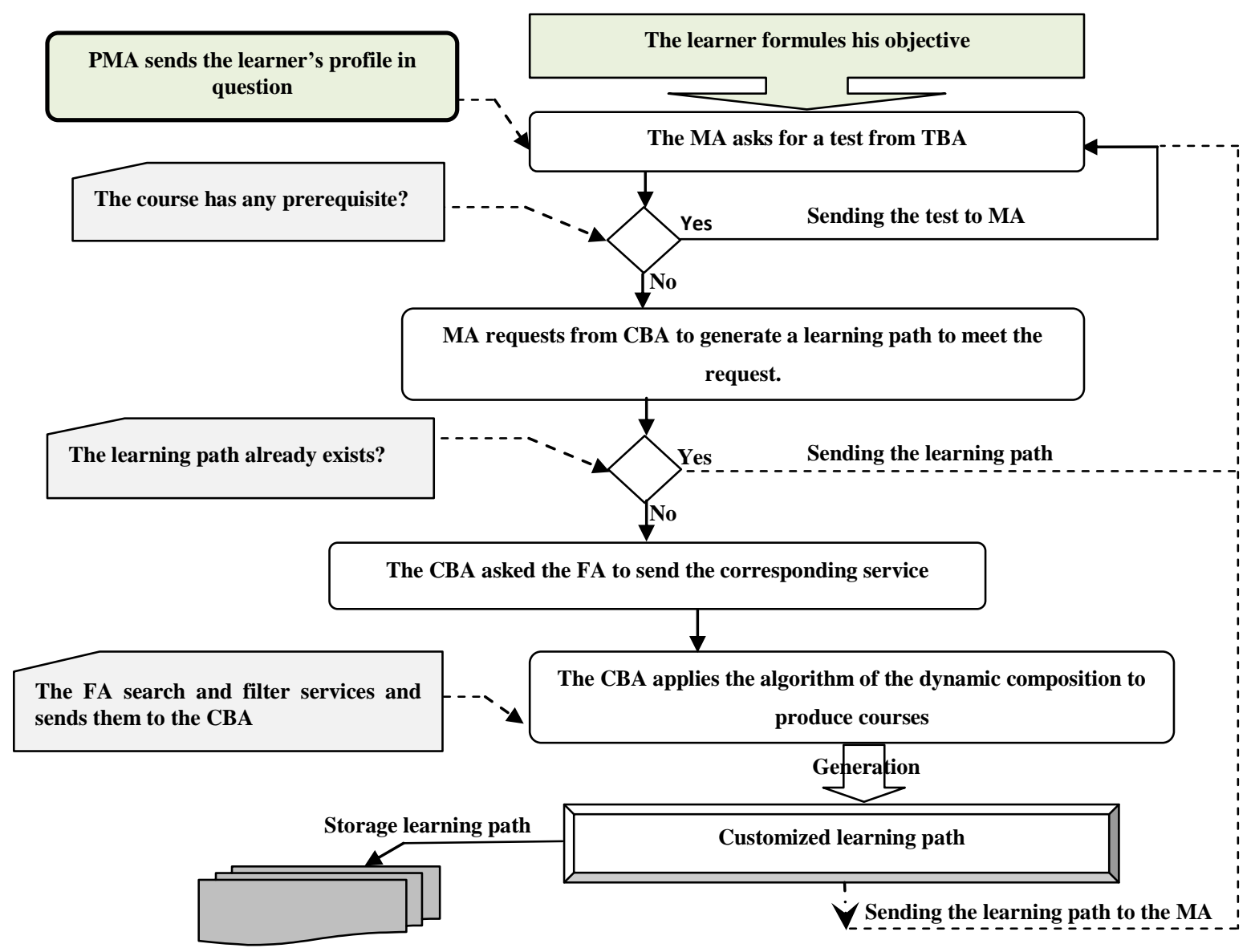

Figure 5: Scenario for a dynamic composition of a course

\subsubsection{Profile Manager Agent (PMA)}

The role of the Profile Manager Agent (PMA) is to create, initialize, store and process the learner profile following a request from the agent interface and may also add a new learner and initialize its level low for all concepts. It will also change the level of the learner on a concept after evaluating the response of the learner on the tests and sends it to new level by the agent interface. Moreover PMA consults, on request from the MA, the level of a learner in one or more concepts to help the CBA and TBA to accomplish their tasks.

\section{A SCENARIO FOR A DYNAMIC COMPOSITION OF A COURSE}

In this section we present a scenario to illustrate how the process of generating a learning paths following a request from a student. When a learner makes his goal, MA demands TBA to send him a test prerequisites. Following the response of TBA, MA demands from CBA to generate learning paths. It consults the ontology of the objectives to determine the type of the goal articulated by the learner, if it's abstract, it will be decomposed into sub-goals. Then it tests if the requested path already exists, a response will be sent directly to the MA. Otherwise, the CBA request from the $\mathrm{FA}$ to send him services that best match with the objective(s) made. FA in his turn searches and filters these services and sends them to the CBA which will organize and assemble to generate a personalized Learning path. This scenario is described in the above (Fig. 5).

\section{CONCLUSION}

To generate automatically learning paths tailored to the profiles of trained and reused by a class of learners with profiles resembling, we proposed a multi-agent and multi-ontologies architecture. This architecture is based on a set of agents communicating and cooperating to meet the demands of learners.

This architecture is the result of technological research and teaching relevant to the extent that the research on which we relied on do not meet all of the features mentioned above. The relevance of the idea focuses on the diversity of approaches (multiontologies, multi-agent) and ensuring the reuse of learning objects through distributed services.

\section{REFERENCES}

[1] J.BRASE\&N.NEDL,Ontologies for Elearning, handbook on ontologies pp.579-598,Springer verlag, 2003.

[2] Staab S, Studer R 2003. Hand book on Ontologies, Springer,. Berlin, Allemagne.

[3] D.HAMELINE Objectifs pédagogiques, en formation initiale et en formation continue. parution 2005. 
[4] Broisin J., « Un Environnement Informatique pour 1'Apprentissage Humain au Service de la Virtualisation et de la Gestion des Objets Pédagogiques », thèse, Université Paul Sabatier Toulouse 3, 2006.

[5] Mary Forehand (2006) : Bloom's taxonomy : Original and revised; http://www.coe.uga.edu/epltt/bloom.htm .

[6] Bloom, B. 1975. "Taxonomie des objectifs pédagogiques". Tome1. Presses de l'Université du Québec.

[7] Chang, W. C., Hsu, H. H., Smith, T. K., \& Wang, C. C. Enhancing SCORM metadata for assessment authoring in e-learning. Journal of Computer Assisted Learning, 305316.2004 .

[8] C. CARABELEA, O. BOISSIER et A. F LOREA : Autonomie dans les systèmes multi-agents : tentative de classification. Actes des 11èmes Journées Francophones sur les Systèmes Multi-Agents (JFSMA), Novembre 2003.

[9] F.BERGENTI, A.POGGI, G.RIMASSA et P.T URCI : Comma : a multi-agent system for corporate memory management. AAMAS '02 : Proceedings of the first international joint conference on Autonomous agents and multi-agent systems, pages 1039-1040,2002.

[10] Foundation for Intelligent Physical Agents. Available at http://www.fipa.org/.

[11] Finin, T. et al. Specification of the KQML agent communication Language. DARPA Knowledge Sharing Initiative External Interfaces Working Group.

[12] Abel MH., Dieng-Kuntz R., Hérin D., Lenne D.,Moulin C., Pompidor P. Langages pour le Web Sémantique et pour le E-Learning. Journée thématique AFIA Web sémantique pour le e-Learning. Plateforme AFIA. Nice, 30 mai. pp. 97-122. - 2005.

[13] CATTEAU O., «Cycle de vie de l'objet pédagogique et ses métadonnées ", thèse, Université Paul Sabatier Toulouse 3, 2008 .
[14] D. Monticolo, V. Hilaire, S. Gomes and A. Koukam, "A Multi Agents Systems for Building Project Memories to Facilitate Design Process", International Journal in Integrated Computer Aided Engineering, accepted in july 2007.

[15] Do Ngoc Kien, Moteur de composition pour le système d'information Sémantique et adaptatif 2006.

[16] Gayo Diallo, Une Architecture à Base d'Ontologies pour la Gestion Unifiée des Données Structurées et non Structurées, Thèse : Université Joseph Fourier - Grenoble I École Doctorale MSTII. 2008

[17] H. Dhraief, W. Nejdl, How are learning Objects Used in learning Processes?, Conference on Educational, World Multimedia, Hypermedia \& Telecommunications, 2002.

[18] Heiwy V., Ducateau C-F. (2003). Un modèle de ressources pédagogiques pour la $\mathrm{FOAD}$, in actes de Environnements Informatiques pour l'Apprentissage Humain, EIAH'2003, Strasbourg, France.

[19] M. Cremene, M. Riveill, C. Martel, C. lophin, C. Miron, Adaptation dynamique de services, 1ère Conférence Francophone sur le Déploiement et la configuration de Logiciels, Grenoble, 2006.

[20] N.ZNIBAR .Construction de parcours pédagogiques individualisés: une approche orientée service. TICE Méditerranée 2007.

[21] S.Dehors,C.Faroun-zuker\&J.P. STROMBONI ,un web sémantique de formation par questionnement, inactes de la journée EIAH, EGC2005, Paris, 2005. 